\title{
Records Review of Musculoskeletal Injuries in Aeromedical Evacuation Personnel
}

Jennifer L. Serres, PhD, Brittany L. Fouts, MS, Susan F. Dukes, PhD, Genny M. Maupin, MPH, Molly E. Wade, MS

From the Department of Aeromedical Research (Serres, Dukes, Maupin), 711th Human Performance Wing, U.S. Air Force School of Aerospace Medicine; the Oak Ridge Institute for Science and Education (Fouts); and Peerless Technologies Corp. (Wade), Wright-Patterson Air Force Base, Dayton, Ohio

Address correspondence to: Brittany L. Fouts, MS, 2510 5th St., Bldg. 840, Wright-Patterson Air Force Base OH 45433. E-mail: brittany.fouts.ctr@us.af.mil.

Background: Aeromedical evacuation providers care for patients during air transport. By applying standard medical practices, oftentimes developed for ground care, these practitioners perform their mission duties under additional physical stress in this unique medical environment. Awkward postures and excessive forces are common occurrences among personnel operating in this domain. Additionally, anecdotal reports highlight the risk of developing musculoskeletal injuries for these providers. Currently, there is limited research focusing on musculoskeletal injuries in aeromedical evacuation providers. 
Purpose: To determine the prevalence of musculoskeletal injuries and associated symptoms in aeromedical evacuation providers to understand the risk and burden of these injuries to military personnel.

Methods: This study utilized a retrospective review of military medical records containing ICD9 codes to investigate the incidence of musculoskeletal injuries within flight nurses and medical technicians compared to their non-flying counterparts from 2006 through 2011. Data were analyzed from 2013 through 2014.

Results: Although musculoskeletal injuries were identified within the test populations, results showed fewer injuries for the aeromedical evacuation populations compared to non-aeromedical evacuation counterparts.

Conclusions: One contributing factor may be a potential under-reporting of musculoskeletal injuries due to the fear of being placed on limited flying status. As flyers, aeromedical evacuation personnel must undergo yearly medical examinations and complete training courses that emphasize proper lifting techniques and physical requirements necessary for the safe and efficient transport of patients on various platforms. These additional requirements may create a healthy worker effect, likely contributing to lower musculoskeletal injuries.

\section{Introduction}

Aeromedical evacuation (AE) personnel are medical providers trained to care for ill and injured patients during transport onboard fixed wing aircraft. Although they are not pilots, AE personnel are considered aircrew. They undergo hours of flight training, are trained to provide safe and efficient transportation of patients, and have significant knowledge of flight procedures, equipment, and life support principles for numerous aircraft platforms. ${ }^{1}$ Over the past decade, the 
AE system has grown, and since the beginning of Operation Iraqi Freedom in March 2003-2010, AE crews conducted over 159,000 patient movements. ${ }^{2}$

AE missions date back to World War II and have utilized a variety of aircraft platforms. ${ }^{3}$ Currently, AE missions commonly utilize C-17, C-130, and K/C-135 aircraft. However, additional platforms may be used as required in specific situations. ${ }^{4}$ Because these aircraft were not initially designed for $\mathrm{AE}$, but rather retrofit with equipment and fixtures to successfully carry out the mission, ergonomic challenges are likely to arise.

Reports indicate that musculoskeletal injuries (MSIs) are the leading healthcare challenge among military personnel. ${ }^{5}$ MSIs are a burden to the military due to increased medical care costs, loss in duty time, possible separation, and decreased quality of life. In AE, ergonomic risk factors that increase the likelihood of MSI include awkward postures, excessive force, and vibrations. ${ }^{6-12}$ Ergonomic challenges are likely to arise during AE tasks in the following categories: aircraft configuration, patient loading, patient care during flight, and patient unloading. Each of these categories brings about unique challenges often linked to a specific type of aircraft. Aircraft configuration typically occurs on the ground or during an inbound flight to pick up patients. During these tasks, the aircraft is prepared for the quantity and acuity of the upcoming patient load. Configuration tasks are aircraft dependent, but typically include setting up stanchions, running lines (i.e., oxygen and electric), and loading equipment. Patient loading and unloading are a combined effort between $\mathrm{AE}$ and ground personnel. Challenges associated with these tasks are also aircraft specific because of configuration differences. A significant portion of the ergonomic risks associated with patient and equipment movement tasks are due to the load. 
Patient care during flight includes a variety of tasks based on patient acuity and varies from platform to platform. AE providers often perform patient and equipment lifting maneuvers in awkward positions due to limited space in the aircraft. Because the platforms used for AE are retrofitted for patient care, excessive bending and stretching movements are also needed to configure the aircraft. Flight stressors including hypoxia, barometric pressure, thermal stress, gravitational forces, noise, vibration, dehydration, and fatigue compound the physical stress of the providers functioning in this challenging environment. ${ }^{13-20}$

Several past studies have focused on the ergonomic risk factors and MSIs associated with providers in civilian healthcare facilities. Back and joint pain are frequently reported, with $52 \%$ of nurses reporting back pain. ${ }^{21-26}$ An investigation of occupational injuries among Canadian air medical personnel through a survey of 106 rotary wing medical providers found an annual injury rate of 3.2 injuries per person. ${ }^{27}$ Injuries including hand lacerations and leg contusions were reported most frequently, followed by back injuries, many of which were attributed to lifting tasks. Although many of these injuries were minor, these findings bring awareness to the complex environment in which these providers operate. Many of the unique challenges associated with air medical care are similar in both rotary wing and fixed wing environments, including limited spacing, patient and equipment lifting requirements, and accelerations.

Although previous studies have focused on civilian healthcare providers and the risk of MSIs, as well as potential confounders for MSIs such as age, there is limited information on the occurrence of MSIs in the military environment. Therefore, the primary goal of this effort is to investigate the incidence of MSIs among aeromedical providers, specifically U.S. Air Force (AF) 
flight nurses and medical technicians, compared to non-flying counterparts. Secondary aims of this study are to identify the most frequent MSIs in the test populations and investigate any relationship between age and MSIs.

\section{Methods}

\section{Research Design}

A retrospective review of military medical records from 2006 through 2011 was conducted from 2013 through 2014 to achieve the objectives of this study. The two following test groups were established from U.S. AF personnel records: flight nurses and medical technicians, hereafter referred to as AE nurses and AE technicians (AETs), respectively. The AE nursing and AET test groups included 1,520 and 2,475 subjects, respectively, from the U.S. AF population. These test groups represented the full identifiable population of experienced (AF Specialty Code [AFSC] Skill Level $\geq 3$ ) AE nurses and AETs (i.e., $\mathrm{N}=$ all). Respective control groups were randomly selected, matching frequency for age and gender during the same time period. AF clinical nurses served as the control for the AE nursing test group, and non-AE AF medical technicians served as the control for the AET test group.

AFSCs were acquired from the AF Personnel Center (AFPC) data and used to identify subjects within the test cohorts. The AE nursing test group included all subjects with AFSC 46F. The existence (or absence) of an Aviation Service Code was also determined from AFPC data and used to ascertain if medical technicians were on AE duty status. The AET test group included subjects with AFSC 4N0 and an Aviation Service Code. Personnel in both test groups with a Skill Level $<3$ were excluded, as these individuals were relatively new in the profession; thus, 
most injuries for these individuals are likely not a result of the cumulative effects of AE duties. Subjects for the respective control groups were randomly selected, frequency matching for age and gender on a 1:1 ratio. The non-flying nursing control group included subjects with AFSC $46 \mathrm{~N}$ (excluding specialties), and the non-AE medical technician control group included subjects with AFSC 4N0 (without an Aviation Service Code). Following the identification of the test and control groups, the following data were collected from AFPC: AFSC, gender, age, and service component (i.e., active duty, Air National Guard, or Air Reserves).

The primary outcome metric for this effort was the number of AE personnel with a clinically diagnosed MSI during the study period. Additional metrics included the total number of clinic visits for MSIs and total number and type of clinically diagnosed MSI occurrences. Military Health Systems (MHS) Mart (M2) was the source of these data. M2 contains clinic visit data for both inpatient and outpatient clinical visits from providers on base (direct) and off base (network). ${ }^{28}$ These data, containing primary ICD-9 diagnosis codes, were linked to the subject by a random number (assigned by data owners) so de-identified data could be provided to the study investigators. The ICD-9 codes of interest were used to determine the incidence of MSIs within the test and control groups and were based on the Barell matrix as modified by Hauret et al. ${ }^{6,29}$ An occurrence was based on primary ICD-9 codes and included duplicates for different conditions in the same year (i.e., if one subject had a primary diagnosis of a shoulder condition during one visit and a primary diagnosis of an ankle injury during another visit, each condition would be reported). However, an occurrence did not include individuals with multiple visits with the same diagnosis in the same year. ICD-9 codes included ranged from 710 to 739 for diseases 
of the musculoskeletal system and connective tissue, and "V" and "E" codes were excluded. In addition to the ICD-9 codes, M2 data fields include year (of care date) and age (at time of care).

\section{Statistical Analysis}

Pearson chi square analysis was performed for the univariate analysis of MSI occurrence for each test group. A $p$-value threshold of 0.05 was set for statistical significance. Descriptive analysis was used to describe the breakdown of injury per body region. This protocol was conducted with approval from the Wright Site IRB at Wright-Patterson Air Force Base in Dayton, $\mathrm{OH}$ with a waiver for informed consent.

\section{Results}

The demographics of the two test groups and two control groups, which were frequency matched for age and gender, are summarized in Table 1 . The majority of nurses fell into the $>40$ years age category (51\%), whereas subjects in the AET test group were more equally distributed across each age group. The AE nursing group had slightly more women $(60 \%)$ than men, and the AET group had slightly more men (65\%) than women. The AE nursing test group had fewer active duty but more Air National Guard and Air Reserve members than the non-AE nursing control group. The AET control group contained fewer active duty and more Air Reserve members compared to the non-AE medical technician group. There was comparable representation of the Air National Guard component between the AET test and non-AE medical technician groups.

The AE nursing test group $(n=1,520)$ had 4,345 clinic visits for 970 occurrences of MSIs affecting 410 AE nurses (27\%) compared to 7,333 clinic visits for 2,320 occurrences of MSIs 
affecting 630 non-AE nurses $(n=1,520,41 \%)$. The AET test group $(n=2,475)$ had 11,268 clinic visits for 2,976 occurrences of MSIs affecting 914 AETs (37\%) compared to 11,587 clinical visits for 3,202 occurrences affecting 1,009 non-AE medical technicians $(n=2,475,41 \%)$. Average clinic visits per injury for AE nurses were 4.5 visits per injury occurrence compared to 3.2 visits per injury occurrence for non-AE nurses. For AETs, the average clinic visits per injury were 3.8 visits per injury occurrence compared to 3.6 visits per injury occurrence for non-AETs.

Table 2 provides a summary of study subjects affected by various MSIs for each of the four study groups. Overall, both non-AE control groups had significantly more subjects affected by MSIs, with $p$-values of $<0.0001$ and 0.006 , respectively. To ensure the service component representation was not influencing these results, a sub-analysis of the Active Duty population was conducted. There was no change in significance for the nursing comparison; however, significance was lost in the medical technician comparison.

Of all subjects affected by MSIs in the vertebral column, the highest percentage in all groups was affected by conditions of the lumbar spine. Both non-AE control groups had significantly more people affected by back injuries compared to their flying counterparts, with $p$-values of $<0.0001$ and 0.006 , respectively. For the upper extremity region, subjects were most frequently treated for conditions of the shoulder for all groups (data not shown). There were no statistically significant differences in the upper extremity category for either comparison. Among lower extremity injuries, subjects were most frequently treated for conditions of the knee and lower leg for all groups (data not shown). There were no statistically significant differences in the lower extremity category for either comparison. 
Table 3 displays the age and gender breakdown of the number of individuals who were affected by an MSI. For both the test and control groups, the $>40$ years age range had the greatest number of individuals who were affected by an MSI during the study period. Clinic visit data are categorized by body region in Figure 1. As evident, clinic visits for MSIs in the back region and the lower extremity occurred most frequently over other body regions for all groups. Figures 2 and 3 provide a breakdown of MSI occurrences by injury types for the AE nursing and AET test groups, respectively. For both the AE nurses and AETs, the greatest burden was MSIs in the lumbar region, followed by the lower extremity region (knee/lower leg).

\section{Discussion}

To the authors' knowledge, this study is the first retrospective review of medical records to investigate the incidence of MSIs for U.S. AF AE providers. Among the test population, 27\% of AE nurses and $37 \%$ of AETs were diagnosed with an MSI. A survey by Sibley and colleagues ${ }^{27}$ in 2005 of 106 Canadian air medical healthcare professionals found 330 acute injuries (including hand lacerations and leg contusions) within a comparable population. Although only $5.6 \%$ of the 330 self-reported injuries required physician intervention, this suggests that the number of injuries/pain from the AE community may be higher if acute injuries were included in the analysis. These minor issues may not require a clinic visit for treatment, but likely add additional physical stress to the providers and may accumulate over time, potentially resulting in a reduction of overall health of the providers. 
Anecdotal reports of back pain in this community are supported by the findings that conditions of the lumbar spine are reported frequently for both test groups. Other studies of medical providers have attributed back pain/injuries to lifting tasks commonly required in these professions. ${ }^{26}$ In addition to standard patient handling responsibilities in a clinical, non-AE setting, AE personnel have the added requirement to move patients often with additional weight from medical devices, and lift and carry considerable equipment loads. Although the occurrence of MSIs was more frequent in the control populations, a related study of post-deployment health assessment forms of this population found conflicting results. In the post-deployment health assessment study, a significantly higher proportion of non-AE nurses compared to AE nurses sought medical attention for MSIs during deployments. However, there was no statistically significant difference between the number of $\mathrm{AE}$ and non-AE nurses being placed on quarters as a result of an MSI during a deployment, suggesting that AE nurses are not seeking medical attention for less severe MSIs. ${ }^{30}$ The higher rate of clinic visits per injury in the AE nursing group described in this article may suggest higher severity, which supports the hypothesis that AE nurses are not seeking medical attention for less severe MSIs. This may be due to the potential fear of being placed on limited flying status if MSIs are reported. An additional consideration is both AE test groups contained higher representation of Air National Guard and Air Reserve members than the control groups. As it is possible that some of these individuals sought medical care from civilian providers, and thus these data would not be included in this analysis, a sub-analysis of the Active Duty groups was conducted. For the nursing comparison, this analysis yielded the same significance as the full analysis; however, significance was lost in the case of the AETs. Therefore, this factor may have influenced the results in the AET comparison. 
Although this study is the first of its kind to conduct a retrospective records review to investigate the burden of MSIs in AE providers, there are some limitations. The main focus was investigating the prevalence of MSIs in AE personnel and comparing this to non-AE personnel; as such, known risk factors for MSIs including BMI, fitness levels, and mental health status were not investigated. Due to limited information of these confounders in the military environment, future work is needed to fully understand the role these contributory factors play in influencing the risk of MSIs in military personnel.

In the civilian healthcare system, there have been studies investigating BMI and the potential risk for MSIs. Preliminary data from a separate study by the research team using survey responses from $44 \mathrm{AE}$ personnel found that BMI did not have a statistically significant effect on the subjective reporting of pain. Additionally, because the military community emphasizes the importance of physical fitness, the authors hypothesize a minimal impact of BMI on the study findings.

Although the fitness levels for each individual in this study were not captured, it is known the AF has strict physical standards for military personnel. As flyers, AE personnel also have to meet additional requirements including an annual flight physical, which their non-AE counterparts do not. ${ }^{1}$ These higher standards and examination requirements may create a healthy worker effect that exceeds general AF physical requirements and likely contributes to the lower rates of MSIs seen in AE personnel compared to non-AE personnel. 
Although there have been documented adverse effects on military personnel during Operation Iraqi Freedom and Operation Enduring Freedom, there is limited information on psychological impacts of these wars on military healthcare professionals. It has been hypothesized that military healthcare professionals on flying status would have a higher incidence of psychological issues than their non-flying counterparts. A separate study by one of the authors found no significant difference between incident post-deployment mental health conditions in Critical Care Air Transport Team (CCATT) members and their non-CCATT counterparts. ${ }^{31}$ Therefore, the mental health status differences of AE providers and non-AE providers in this study are not hypothesized to be a major contributor to the differences identified in this study.

\section{Conclusions}

Physical stresses associated with the work of healthcare providers have been well documented. ${ }^{21-}$

${ }^{26}$ Thus, the authors hypothesized a higher occurrence of MSIs in AE providers compared to their non-AE counterparts due to their austere work environment. However, the research team discovered this was not the case for the subjects analyzed in this study. It is possible this is because of the additional training on proper lifting techniques that occurs as part of the basic and formal training courses for both AE nurses and AETs, as outlined in AFI 11-2AE. ${ }^{1}$ In addition to the formal ergonomic training, most AE squadrons stress the importance of proper lifting as part of their patient safety programs. Furthermore, AF personnel on flying status are required to complete an additional annual flight physical to ensure they meet flying requirements as outlined in AFI 48-123. ${ }^{32}$ The additional ergonomic training, patient safety programs, medical examinations, and higher physical standards required of AE personnel may cause a healthy worker effect, which is likely a significant factor in the lower rates of MSIs seen in AE providers. It is possible these findings result from under-reporting of injuries, linked to fear of 
being placed on limited flying status. More likely, the findings result from a combination of these factors. However, these results do highlight an important issue that costs the AF significantly in terms of medical costs and lost duty time and also causes pain, sometimes longlasting, to service members. Therefore, future work should focus on recommendations to reduce the risk of these injuries in the $\mathrm{AE}$ environment.

\section{Acknowledgments}

This work was funded by the Department of the Air Force, 711 th Human Performance Wing, Defense Health Program. This research was supported in part by an appointment to the Student Research Participation Program at the U.S. Air Force Research Laboratory, 711 th Human Performance Wing, administered by the Oak Ridge Institute for Science and Education through an interagency agreement between the U.S. Department of Energy and the U.S. Air Force Research Laboratory. The views expressed in this article are those of the authors and do not necessarily reflect the official policy or position of the Air Force, the Department of Defense, or the U.S. Government.

No financial disclosures were reported by the authors of this paper.

\section{References}

1. United States Department of the Air Force. Aeromedical evacuation aircrew training (AFI 11-2AE, Volume 1). 2013. http://static.epublishing.af.mil/production/1/af_a3_5/publication/afi11-2aev1/afi11-2aev1.pdf. 
2. Sturkol ST. House of Representatives resolution honors aeromedical evacuation Airmen. Air Mobility Command. 2010. http://www.amc.af.mil/news/story.asp?id=123224648.

3. Whitcomb D. Call sign "Dustoff": a history of U.S. Army aeromedical evacuation from conception to hurricane Katrina. Frederick, MD: Office of the Surgeon General, Borden Institute, 1947.

4. Guerdan BR. United States Air Force aeromedical evacuation - a critical disaster response resource. Am J Clin Med 2011;8(3):153-6.

5. Yancosek KE, Roy T, Erickson M. Rehabilitation programs for musculoskeletal injuries in military personnel. Curr Opin Rheumatol 2012;24(2):232-6. http://dx.doi.org/10.1097/BOR.0b013e3283503406.

6. Hauret KG, Jones BH, Bullock SH, Canham-Chervak M, Canada S. Musculoskeletal injuries description of an under-recognized injury problem among military personnel. Am J Prev Med 2010;38(1 Suppl):S61-70. http://dx.doi.org/10.1016/j.amepre.2009.10.021.

7. Taneja N, Pinto LJ. Diagnostic categories among 232 military aircrew with musculoskeletal disabilities. Aviat Space Environ Med 2005;76(6):581-5.

8. Grossman A, Nakdimon I, Chapnik L, Levy Y. Back symptoms in aviators flying different aircraft. Aviat Space Environ Med 2012;83(7):702-5. http://dx.doi.org/10.3357/ASEM.3225.2012.

9. Nissen LR, Guldager B, Gyntelberg F. Musculoskeletal disorders in main battle tank personnel. Mil Med 2009;174(9):952-7. http://dx.doi.org/10.7205/MILMED-D-03-5508.

10. Gaydos SJ. Low back pain: considerations for rotary-wing aircrew. Aviat Space Environ Med 2012;83(9):879-89. http://dx.doi.org/10.3357/ASEM.3274.2012. 
11. Yassi A. Repetitive strain injuries. Lancet 1997;349(9056):943-7. http://dx.doi.org/10.1016/S0140-6736(96)07221-2.

12. Yassi A. Work-related musculoskeletal disorders. Curr Opin Rheumatol 2000;12(2):124-30. http://dx.doi.org/10.1097/00002281-200003000-00006.

13. Blumen IR, Rinnert KJ. Altitude physiology and the stresses of flight. Air Med J 1995;14(2):87-100. http://dx.doi.org/10.1016/S1067-991X(95)90102-7.

14. Lamb $\mathrm{D}$. The documentation of pain management during aeromedical evacuation missions. Nurs Clin North Am 2010;45(2):249-60. http://dx.doi.org/10.1016/j.cnur.2010.02.012.

15. Schmelz JO, Bridges EJ, Wallace MB, et al. Comparison of three strategies for preventing hypothermia in critically injured casualties during aeromedical evacuation. Mil Med 2007;172(3):322-6.

16. Makley AT, Belizaire R, Campion EM, et al. Simulated aeromedical evacuation does not affect systemic inflammation or organ injury in a murine model of hemorrhagic shock. Mil Med 2012;177(8):911-6. http://dx.doi.org/10.7205/MILMED-D-11-00385.

17. Earnest RE, Sonnier DI, Makley AT, et al. Supplemental oxygen attenuates the increase in wound bacterial growth during simulated aeromedical evacuation in goats. J Trauma Acute Care Surg 2012;73(1):80-6. http://dx.doi.org/10.1097/TA.0b013e31824cf215.

18. Bridges E, Schmelz J, Evers K. Efficacy of the blizzard blanket or blizzard blanket plus thermal angel in preventing hypothermia in a hemorrhagic shock victim (Sus scrofa) under operational conditions. Mil Med 2007;172(1):17-23.

19. Kalns J, Cox J, Baskin J, Santos A, Odland R, Fecura S Jr. Extremity compartment syndrome in pigs during hypobaric simulation of aeromedical evacuation. Aviat Space Environ Med 2011;82(2):87-91. http://dx.doi.org/10.3357/ASEM.2853.2011. 
20. Barnes SL, Branson R, Gallo LA, Beck G, Johannigman JA. En-route care in the air: snapshot of mechanical ventilation at 37,000 feet. J Trauma 2008;64(2 Suppl):S129-34. http://dx.doi.org/10.1097/TA.0b013e318160a5b4.

21. Gropelli T, Corle K. Assessment of nurses' and therapists' occupational musculoskeletal injuries. Medsurg Nurs 2011;20(6):297-303.

22. Ngan K, Drebit S, Siow S, Yu S, Keen D, Alamgir H. Risks and causes of musculoskeletal injuries among health care workers. Occup Med (Lond) 2010;60(5):389-94. http://dx.doi.org/10.1093/occmed/kqq052.

23. Alnaser MZ. Occupational musculoskeletal injuries in the health care environment and its impact on occupational therapy practitioners: as systematic review. Work 2007;29(2):89-100.

24. Hunter B, Branson M, Davenport D. Saving costs, saving health care providers' backs, and creating a safe patient environment. Nurs Econ 2010;28(2):130-4.

25. Karahan A, Kav S, Abbasoglu A, Dogan N. Low back pain: prevalence and associated risk factors among hospital staff. J Adv Nurs 2009;65(3):516-24. http://dx.doi.org/10.1111/j.1365-2648.2008.04905.x.

26. Menzel NN. Underreporting of musculoskeletal disorders among health care workers: research needs. AAOHN J 2008;56(12):487-94. http://dx.doi.org/10.3928/0891016220081201-06.

27. Sibley AK, Tallon JM, Day AL, Ackroyd-Stolarz, S. Occupational injuries and stressors among Canadian air medical health care professionals in rotor-wing programs. Air Med J 2005;24(6):252-7. http://dx.doi.org/10.1016/j.amj.2005.08.001.

28. Office of the Assistant Secretary of Defense for Health Affairs (OSAD(HA)) TRICARE Management Activity (TMA). Guide for DoD researchers of using MHS data. 2012. 
http://www.tricare.mil/tma/privacy/hrpp/downloads/Guide\%20for\%20DoD\%20Researchers \%20on\%20Using\%20MHS\%20Data.pdf.

29. Barell V, Aharonson-Daniel L, Fingerhut LA, et al. An introduction to the Barell body region by nature of injury diagnosis matrix. Inj Prev 2002;8(2):91-6. http://dx.doi.org/10.1136/ip.8.2.91.

30. Serres JL, Fouts B, Dukes S, Maupin G, Wade M. Characterizing self-reported musculoskeletal injuries in aeromedical evacuation personnel: review of post-deployment health assessments. The Society of Federal Health Professionals Annual Meeting; 2013 Nov 4-8; Seattle, WA.

31. Tvaryanas AP, Maupin GM. Risk of incident mental health conditions among critical care air transport team members. Aviat Space Environ Med 2014;85:30-8. http://dx.doi.org/10.3357/ASEM.3782.2014.

32. United States Department of the Air Force. Medical examinations and standards (AFI-48123). 2013. http://static.e-publishing.af.mil/production/1/af_sg/publication/afi48-123/afi48123.pdf 


\section{List of Figures}

Figure 1. MSI clinic visit summary for tests and controls (2006-2011)

$\mathrm{AE}$, aeromedical evacuation; MSI, musculoskeletal injury

Figure 2. Occurrence of MSI clinic visits by body region for AE nurses (2006-2011)

$\mathrm{AE}$, aeromedical evacuation; MSI, musculoskeletal injury

Figure 3. Occurrence of MSI clinic visits by body region for AETs (2006-2011)

AETs, aeromedical evacuation technicians; MSI, musculoskeletal injury 
Table 1. Demographics of AE nurses, AETs and controls from 2006 to 2011

\begin{tabular}{|c|c|c|c|c|}
\hline Demographic & $\begin{array}{c}\text { AE nurses } \\
(\mathrm{n}=1,520)\end{array}$ & $\begin{array}{c}\text { Non-AE } \\
\text { nurses } \\
(n=1,520) \\
\end{array}$ & $\begin{array}{c}\text { AETs } \\
(\mathrm{n}=2,475)\end{array}$ & $\begin{array}{c}\text { Non-AE medical } \\
\text { technicians } \\
(\mathrm{n}=2,475)\end{array}$ \\
\hline \multicolumn{5}{|l|}{ Age } \\
\hline $18-24$ & $14(1)$ & $14(1)$ & $517(21)$ & $517(21)$ \\
\hline $25-30$ & $164(11)$ & $164(11)$ & $617(25)$ & $617(25)$ \\
\hline $31-35$ & 237 (16) & 237 (16) & $416(17)$ & $416(17)$ \\
\hline $36-40$ & $328(22)$ & $328(22)$ & $424(17)$ & $424(17)$ \\
\hline Over 40 & $777(51)$ & $777(51)$ & $501(20)$ & $501(20)$ \\
\hline \multicolumn{5}{|l|}{ Gender } \\
\hline Male & $603(40)$ & $603(40)$ & $1,607(65)$ & $1,607(65)$ \\
\hline Female & $917(60)$ & $917(60)$ & $868(35)$ & $868(35)$ \\
\hline \multicolumn{5}{|l|}{ Component } \\
\hline Active Duty & $412(27)$ & $929(61)$ & $691(28)$ & $1,139(46)$ \\
\hline Guard & $387(26)$ & $177(12)$ & $579(23)$ & $489(20)$ \\
\hline Reserve & $721(47)$ & $414(27)$ & $1,205(49)$ & 847 (34) \\
\hline
\end{tabular}

$\mathrm{AE}$, aeromedical evacuation; AETs, aeromedical evacuation technicians 
Table 2. AE nurses, AETs and controls with an MSI primary diagnosis from 2006 to $2011^{\mathrm{a}}$

\begin{tabular}{|c|c|c|c|c|c|c|}
\hline MSI & $\begin{array}{l}\text { Test } \\
\text { group: } \\
\mathrm{AE} \\
\text { nurses }\end{array}$ & $\begin{array}{l}\text { Control } \\
\text { group: } \\
\text { Non-AE } \\
\text { nurses } \\
\end{array}$ & p-values ${ }^{b}$ & $\begin{array}{l}\text { Test } \\
\text { group: } \\
\text { AETs }\end{array}$ & $\begin{array}{l}\text { Control group: } \\
\text { Non-AE } \\
\text { medical } \\
\text { technicians }\end{array}$ & p-values \\
\hline $\begin{array}{l}\text { Vertebral } \\
\text { Column total }\end{array}$ & 181 & 369 & $<0.0001$ & 497 & 576 & 0.006 \\
\hline $\begin{array}{l}\text { Upper } \\
\text { Extremity total }\end{array}$ & 90 & 98 & 0.549 & 180 & 180 & 1.00 \\
\hline $\begin{array}{l}\text { Lower } \\
\text { Extremity total }\end{array}$ & 131 & 156 & 0.121 & 220 & 231 & 0.584 \\
\hline $\begin{array}{l}\text { Unclassified } \\
\text { by site, total }\end{array}$ & 8 & 7 & 0.791 & 17 & 22 & 0.420 \\
\hline Total & 410 & 630 & $<0.0001$ & 914 & 1,009 & 0.006 \\
\hline
\end{tabular}

${ }^{\mathrm{a}}$ Only primary ICD-9 codes were included in the data without repeat visits

${ }^{\mathrm{b}}$ Pearson chi square test

Note: Boldface indicates statistical significance

AE, aeromedical evacuation; AETs, aeromedical evacuation technicians; MSI, musculoskeletal injury 
Table 3. Demographics of AE nurses, AETs and controls from 2006 to 2011 affected by an MSI

\begin{tabular}{ccccc}
\hline Demographic & $\begin{array}{c}\text { AE nurses } \\
(\mathrm{n}=410)\end{array}$ & $\begin{array}{c}\text { Non-AE } \\
\text { nurses } \\
(\mathrm{n}=630)\end{array}$ & $\begin{array}{c}\text { AETs } \\
(\mathrm{n}=914)\end{array}$ & $\begin{array}{c}\text { Non-AE medical } \\
\text { technicians } \\
(\mathrm{n}=1,009)\end{array}$ \\
\hline Age & & & & \\
$18-24$ & $2(0.5)$ & $1(0.2)$ & $123(13)$ & $174(17)$ \\
$25-30$ & $27(7)$ & $46(7)$ & $184(20)$ & $239(24)$ \\
$31-35$ & $44(11)$ & $62(10)$ & $158(17)$ & $140(14)$ \\
$36-40$ & $75(18)$ & $136(22)$ & $192(21)$ & $198(20)$ \\
Over 40 & $262(64)$ & $385(61)$ & $257(28)$ & $258(26)$ \\
Gender & & & & $640(63)$ \\
Male & $140(34)$ & $236(37)$ & $595(65)$ & $369(37)$ \\
Female & $270(66)$ & $394(63)$ & $318(35)$ &
\end{tabular}

AE, aeromedical evacuation; AETs, aeromedical evacuation technicians; MSI, musculoskeletal injury 

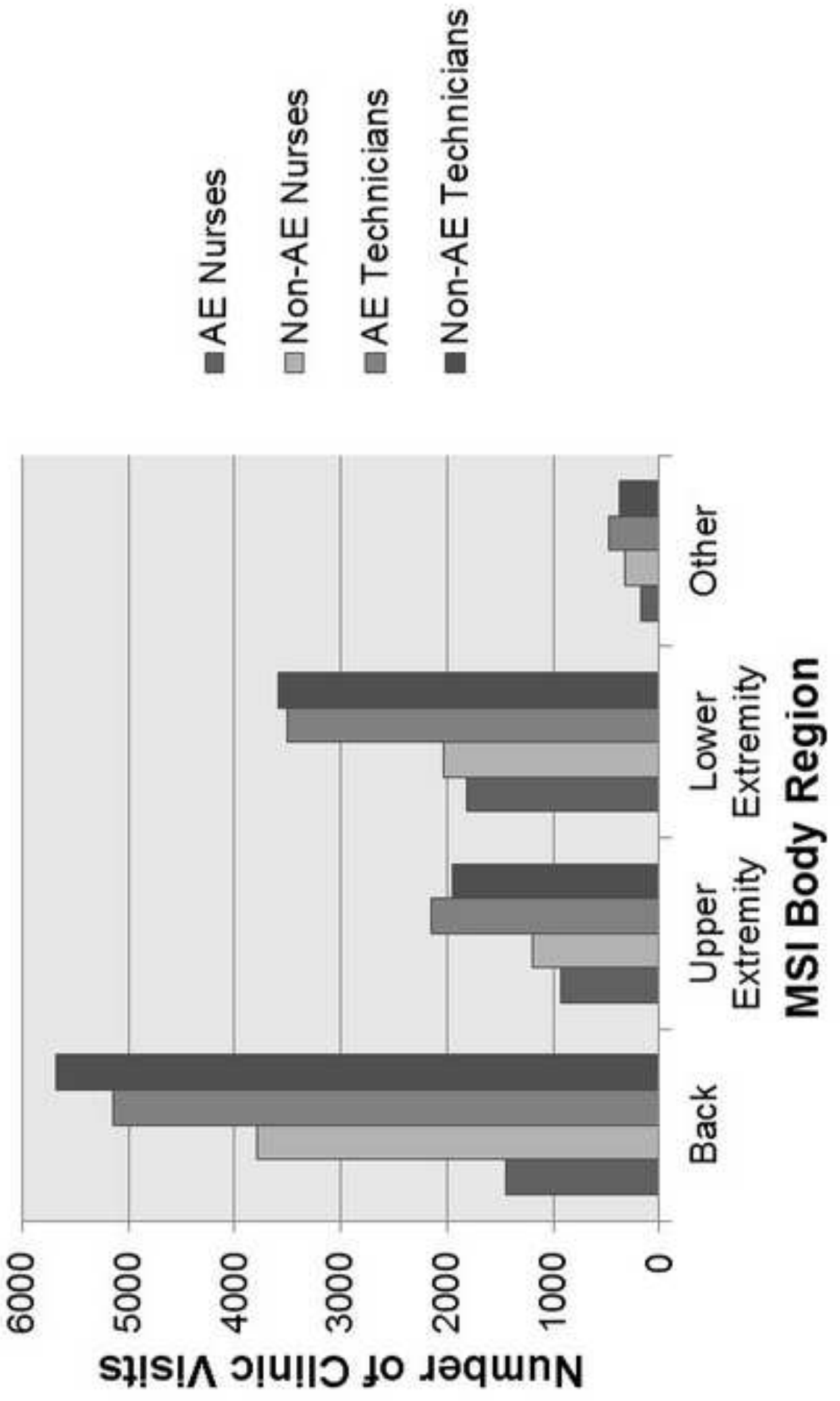


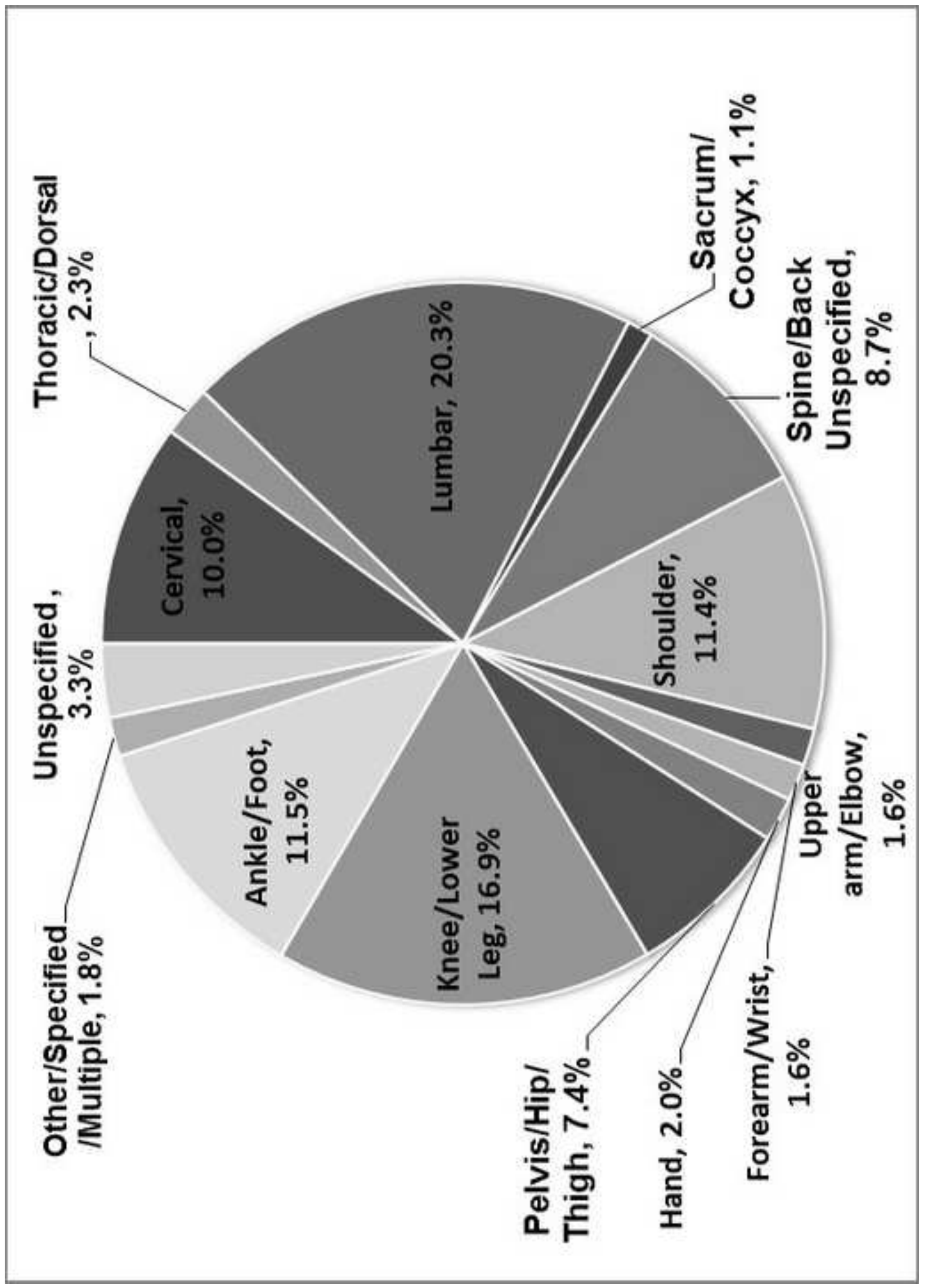




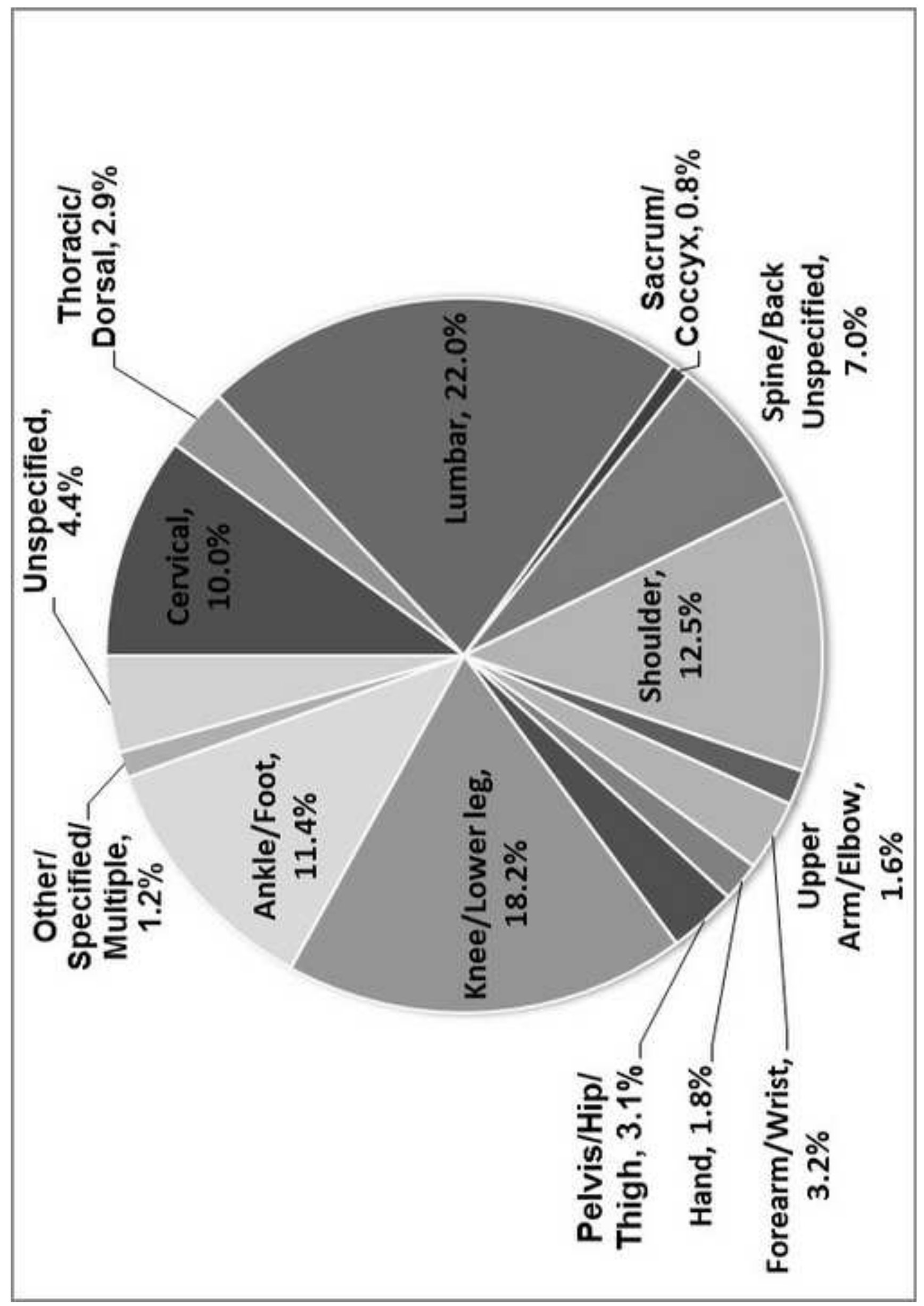

